\title{
Geographical Distribution of Malvaceae: Lavatera maritima=Malva subovataa in Coastal Region of Tlemcen, Algeria
}

\author{
S. Ghalem, I. Abdeli', F. Hassani ${ }^{2}$ and S.I. Bouayad ${ }^{2}$ \\ Laboratory of Ecology and Management of Natural Ecosystems, SNV-STU Faculty of Tlemcen University \\ ${ }^{1}$ Higher School of Applied Sciences, Tlemcen, Algeria \\ Laboratory of Natural and bio-actives Substances, Faculty of Science, University, Tlemcen, Algeria \\ ${ }^{2}$ Laboratory of Ecology and Management of Natural Ecosystems, Faculty SNV-STU University of Tlemcen \\ E-mail: sarah.ghalem@outlook.com
}

\begin{abstract}
The végétation of the Tlemcen region, presents the study of plant diversity. In order to give an overview of the location of L.maritima, developed a map of the stations (Chaib rasso, Marsa ben m'hidi, Bider Mouskarada). The dominance of therophyte species compared to chamaephytes and phanerophytes, which testifies to a very strong anthropogenic action.
\end{abstract}

Keywords: Lavatera maritima, Chaib rasso, Mouskarda, Bider, Marsa ben m'hidi, Therophyte

Mapping is the basis of ecological management of ecosystems (Ferka 2006) and remains necessary tool for all forms of development and understanding of an ecosystem, allowing in-depth knowledge of the environment, its potential and its optimal uses. Cartographic representations of the vegetation cover are essential working documents for many studies. A vegetation map can be viewed in different ways, as a physiognomy map showing the present state of vegetation, or as a land use map. Thematic maps remain necessary tools for all forms of development and understanding of an ecosystem. (Belhassini 2011). The purpose of this article, is to show that the coastal region of Tlemcen has a very diverse flora and very related to the different disturbance factors. The map we have made includes the coastlines of the four stations (Marsa ben m'hidi 1 and 2, Bider and Mouskarda) on the northern slopes of the Tlemcen region. It gives us a general overview of the range of our lavatère and also allows us to highlight the current state of the study areas.

\section{MATERIAL AND METHODS}

Concerning the mapping of the types of plant groups in L. maritima relating to this zone, the maps were drawn up which are used vegetation formation maps, Floristic surveys carried out in the field. The Map.info 7.5 data procession software was used. The choice of the scale of the map is delicate and requires a lot of attention. If the chosen scale is too small, it is not possible to represent complex phenomena without the risk of making the map confusing and difficult to read and if the scale is too large, the territory represented has only a small extent and it is not possible to obtain a synthetic view of the main lines of the vegetation of the region studied. For this reason, medium scales are the most widely used, except in special cases. (Barka 2016). The zone 2 is made up of: Lavatera maritima, Aegilops triuncialis, Ferula communis, Convolvulus althaeoides, Scolymus hispanicus, Withania frutescens, Olea europea, Papaver rhoeas, Reseda alba, Lavendula dentata, Inula viscosa, Hordeum murinum. The flora used for the identification of the taxa collected include the new flora of Algeria (Quezel and Santa 1963) and The great flora of France and neighboring countries Bonnier and Douin (1990).

\section{RESULTS AND DISCUSSION}

As biological types are conditioned by environmental factors and physiognomic expression, reflects the environmental conditions. The enumeration of species by biological type is carried out on all the species inventoried in each station (Kerzabi 2017). In present study retained five forms ofr biological types (Table 2, Fig. 2), from the global list of recorded species, and can determine the number of each biological type.

Bider msirda fougara: Therophytes and hemicryptophytes are best represented with the same percentage of $(40 \%)$, followed by chamaephytes (15\%), Geophytes (5\%) and absence of Phanerophytes.

Marsa Ben-mehidi 1: The therophytes are represented with a percentage of $(57.69 \%)$, Chamaéphytes and the hemicryptophytes $(19.23 \%)$ and low percentage of the phanerophytes of (3.84\%).

Marsa Ben-mehidi 2: The therophytes are represented with a percentage of $(50 \%)$, the followed by chamaéphytes and the hemicryptophytes (15.78\%), Geophytes (10.52\%),finally 
Table 1. Geographical data for Zone 2

\begin{tabular}{lll}
\hline Code & Longitude & Latitude \\
\hline Bider msirda fougara & $002^{\circ} 02 \mathrm{~W}$ & $35^{\circ} 03 \mathrm{~N}$ \\
Marsa ben mehidi 1 & $002^{\circ} 11 \mathrm{~W}$ & $35^{\circ} 04 \mathrm{~N}$ \\
Marsa ben mehidi 2 & $002^{\circ} 11 \mathrm{~W}$ & $35^{\circ} 04 \mathrm{~N}$ \\
Mouskarda & $002^{\circ} 11 \mathrm{~W}$ & $35^{\circ} 05 \mathrm{~N}$ \\
\hline
\end{tabular}

Table 2. Number of biological types for each station

\begin{tabular}{lccccc}
\hline Station biological type & $\begin{array}{c}\text { Phanerophyte } \\
\text { Ph }\end{array}$ & $\begin{array}{c}\text { Chamaephyte } \\
\text { Ch }\end{array}$ & $\begin{array}{c}\text { Hemicryptophyte } \\
\text { He }\end{array}$ & $\begin{array}{c}\text { Geophyte } \\
\text { Ge }\end{array}$ & $\begin{array}{c}\text { Therophyte } \\
\text { Th }\end{array}$ \\
\hline Marsa ben m'hidi 1 & 01 & 05 & 05 & 00 & 15 \\
Marsa ben m'hidi 2 & 04 & 06 & 06 & 03 & 19 \\
Mouskarda & 03 & 08 & 06 & 05 & 23 \\
Bider & 00 & 03 & 08 & 01 & 08 \\
\hline
\end{tabular}

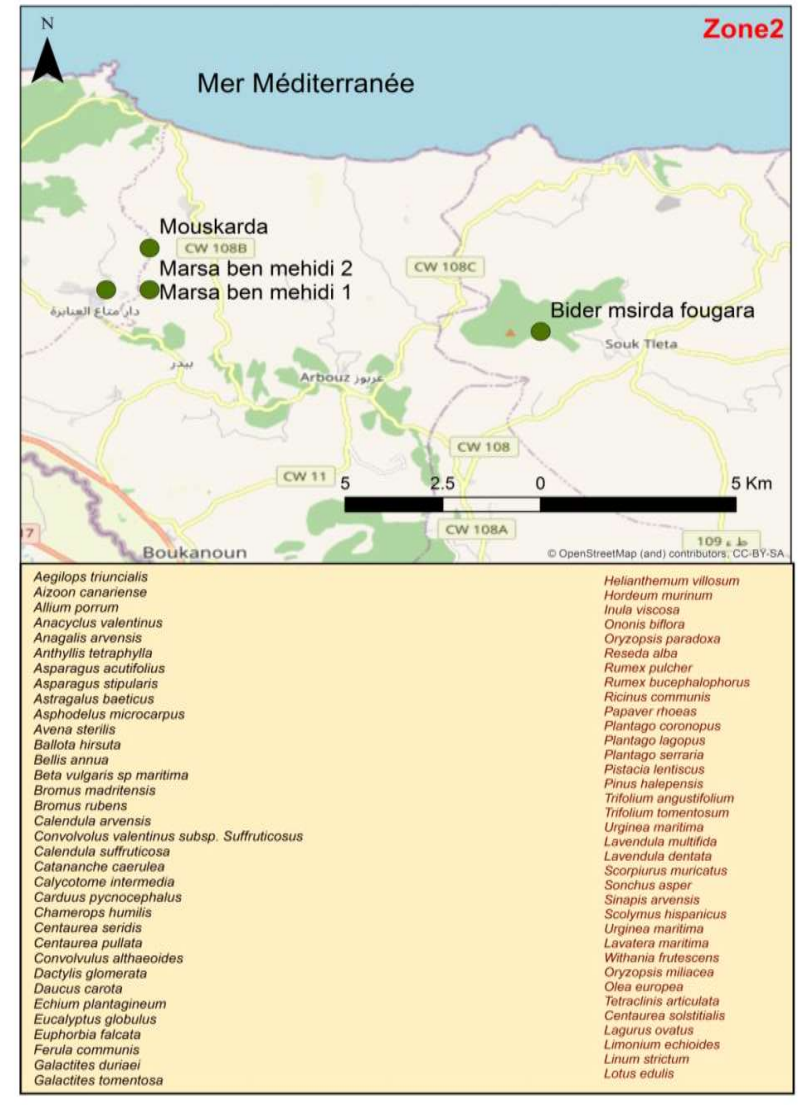

Fig. 1. Presence of L.maritima in zone 2

a very low percentage of Phanerophytes of (7.89\%).

Mouskarda: The therophytes are represented with a percentage (51.11\%), followed by chamaéphytes (17.77\%), hemicryptophytes (13.33\%), Geophytes (11.11\%), finally a very low percentage of Phanerophytes with (6.66\%). Despite the low participation of phanerophyte species in study area, they are dominant by their biomass, they thus constitute forests and preforests,
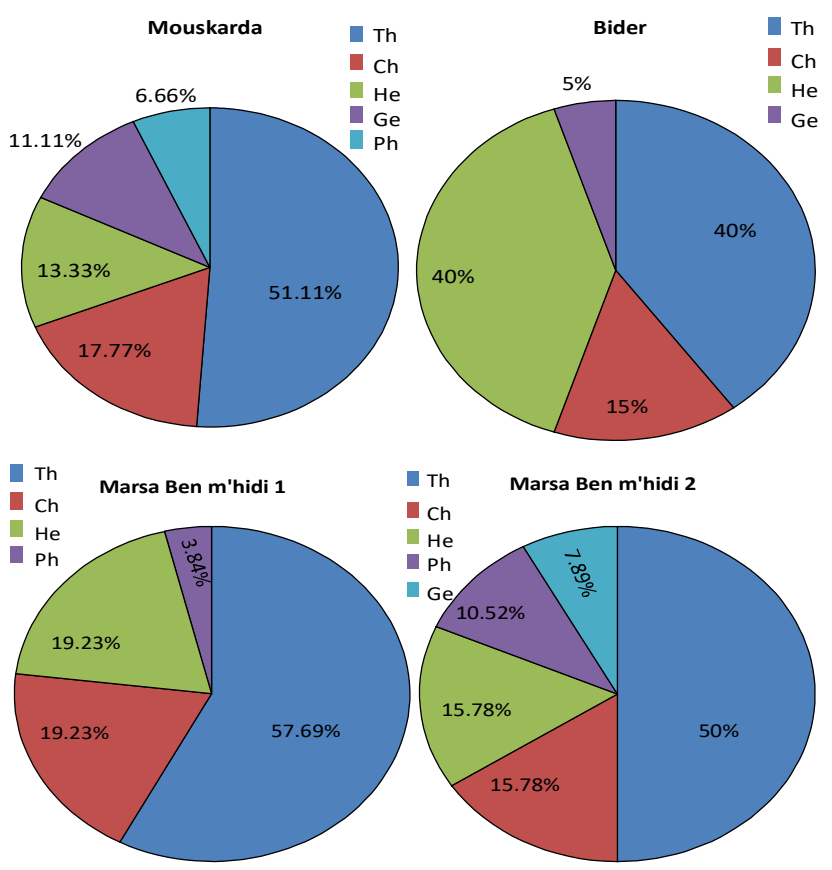

Fig. 2. Percentage of biological types from each station

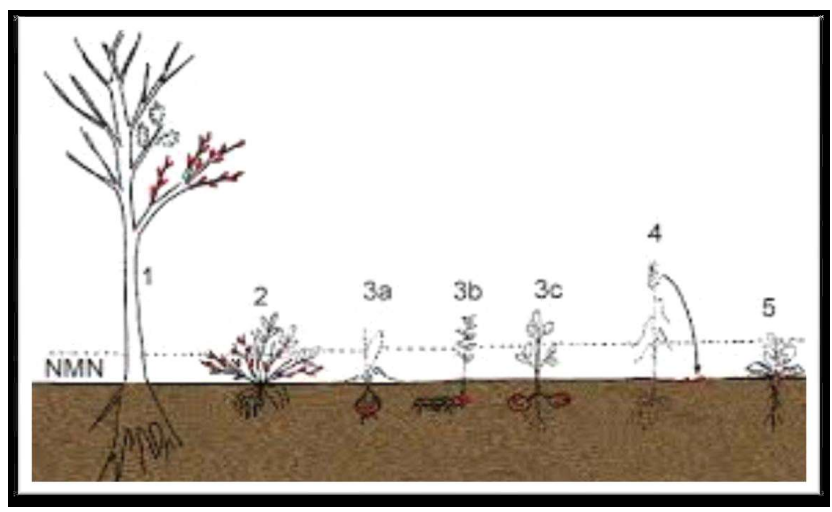

1: Phanerophytes - 2: Chamaephytes - 3: Geophytes (3a with bulb, 3b with rhizome and $3 \mathrm{c}$ with tuber) 4: Therophytes - 5 : Hemicryptophytes

Fig. 3. The biological types (Raunkiaer 1934) 


\section{CONCLUSION}

The dominance of the Therophytization trait is linked to the invasion of annual species disseminated by the striking action of man and his herds, especially in the study area.The production of a distribution map of the groups in Lavatera maritima in the region of North West Algeria helps us to identify the current state of the natural distribution area of this taxon. Finally the cartographic study has shown the importance of the floral procession linked to Malva subovata or Lavatera maritima in the coast with a very large number.

\section{REFERENCES}

Barka F 2016. Study of matorral groupings on the coast of the Tlemcen region. Phytoecological aspects and mapping. p. 278.

Received 12 August, 2021; Accepted 12 December, 2021
Belhassini F 2011. Contribution to a floristic and biogeographic study of the matorrals of the southern slope of the Tlemcen region $\mathrm{p}$. 119.

Bonnier and Douin 1990. The great flora in color. Ed. Belin. Paris. Belin "3". pp: 214.

Ferka Z 2006. Impact of the spatio-temporal occupation of spaces on the conservation of the forest ecosystem case of the municipality of Tessala, willaya of Sidi-Bel-Abbès, Algeria. Same. Mag. Forest. Univ. Tlemcen. 126p + annexes.

Kerzabi R 2017. L'effet anthropique sur la végétation halophyte en milieu semi-aride et

aride de l'Oranie ; Dynamique de la végétation en relation avec les facteurs édaphiques.1-7-13-16-51-165-200p.

Quezel P and Santa S 1962-1963. New flora of Algeria and desert regions southern. CNRS. Paris. 2 flights. p. 1170

Raunkiaer C1934. Biological types with reference to the adaptation of plants to survive the unfavourable season. in Raunkiaer. 1$2 p$. 